the lack of knowledge of the processes of collision and coalescence between small droplets, which hinders correct appreciation of the importance of the coalescence mechanism of rain formation. $\mathrm{He}$ showed that showers form purely by this mechanism in the Caribbean, and that the mechanism still operates in the larger clouds of the eastern Lnited States, whereas the Bergeron-Findeisen ice-crystal mechanism might be the more important in the arid south-western States. These challenging statements and striking flight-observations provoked a lively discussion.

On the second day, Mr. F. H. Ludlam (Imperial College) pointed out that the partitioning (into micro-, macro- and synoptic-physics) of cloud studies, though convenient, must not be made too rigid. It is particularly important that meteorologists (especially dynamicists) should develop the difficult studies of individual clouds, in order that the meteorological conditions within which the microphysical processes operate should be better understood. He illustrated the links which must be sought between the main divisions of the subject by describing some features of convection clouds in the lower troposphere (cumulus), the upper troposphere (cirrus), and the stratosphere (noctilucent clouds). It has been found in Sweden that showers form in cumulus if their tops exceed a rather well-defined level which varies from day to day, and at which the temperature varies from $-4^{\circ} \mathrm{C}$. to about $-25^{\circ} \mathrm{C}$. It seems that the coalescence mechanism is responsible for both tho shower formation and the extensive production of crystals in the cloud tops. Studies of the other clonds show that there must be a source of atmospheric nuclei, not only at the Earth's surface, but also in the high atmosphere. Examinations of the outer solar corona and the zodiacal light support the hypothesis that cosmic dust settles into the atmosphere at a rate sufficient to provide practically all the nuclei presont in the upper troposphere, and to provide concentrations of about $100 / \mathrm{cm}^{3}$ of Aitken nuclei near the ground. The implications of such a universal pollution of practically invisible particles (diameter about $10^{-5} \mathrm{~cm}$.) need careful consideration.

Mr. J. S. Sawyer (Meteorological Office) discussed the properties of the great layer-cloud systems which are associated with cyclones and fronts. The computations of the vertical motion in these atmospheric disturbances, which can now bo made with the help of machines, are incapable of resolving internal details that can bo deduced from rainfall records and fight investigations. Probably the formation of these cloud systems plays a significant part in cyclone development, for their presence reduces certain braking-effects due to the stable stratification of the atmosphere. Mr. Sawyer described new models of the vertical structure of frontal clouds, based mainly on observations of the Meteorological Research Flight.

On the final afternoon Prof. J. S. Marshall (McGill University) spoke on radar studies of clouds and precipitation. Ho described the use of millimetre radar, which can 'see' a high proportion of nonprecipitating clouds, and of centimetre radar to obtain a three-dimensional representation of snow streamers, which are a characteristic feature of about half of the winter snowfall in Canada. These streamers fall from self-propagating convective cells. He also reviewed new information on the formation of 'bright-band' precipitation echoes, radar evidence of the importance of the coalescence mechanism in shower formation, radar 'angels' at a sea-breeze front, the peculiar hook-shaped echoes associated with tornados, and the spiral-band echoes received from tropical cyclones.

The last contribution was from Dr. T. W. Wormell (Cambridge) on the generation of electricity by thunderstorms. He summarized existing evidence on the distribution of electricity in thunderclouds, and on the rate of charge re-separation in the intervals between lightning discharges. After outlining the classical and more recent theories of charge generation, he remarked that strong electrical activity is found only in clouds containing ice particles. 'The most recent theory of charge generation, due to Reynolds in New Mexico, attributes it to collisions occurring between ice crystals and small hailstones which are growing by sweeping up supercooled droplets, and which have a surface temperature a degree or two higher than the crystals owing to the release of the latent heat of fusion. This promising theory is now being developed quantitatively; but it is lilsely to have competition, for a new paper is expected from C. T. R. Wilson, and a proposal by Vonnegut that the largo cumulus is for macrophysical reasons an influence machine is attracting attention.

The conference was notable for the very substantial participation of overseas physicists and meteorologists, and for the enormous range of the topics raised. The expansion of cloud physics has been so great that it is now impossible to describe the progress of research other than cursorily in a two-day meeting, even if no reference is made to the possibilities of weather modification which have been such a strong spur to recent work. It was unfortunate that a smog reduced the attendance of the conference; but the audience each day exceeded one hundred and fifty, and its members must have been impressed with the present scope of the subject and the vigour with which its many problems are being attacked.

F. H. LUdLAM

\section{BRITISH COUNCIL}

\section{TWENTY-FIRST ANNIVERSARY REPORT}

THE twenty-first anniversary report of the British Council*, which includes a congratulatory message and a tribute to the services of the Council from the Prime Minister, covers the year 1954-55 and is unusually brief. Acceptance of the broad principles of the Drogheda Report was only announced by tho Government in December 1954, but the effect of the new policy, which included the devotion of $£ 100,000$ to the expansion of the Overseas Information Service (including the Council) in 1954-55 and again in 1955-56, has already been felt. For the first time in seven years the Council's grant-in-aid was not reduced, and negotiations were commenced with the Treasury for the establishment of an amalgamated Council service, for the improvement of conditions of service, and for the introduction of a satisfactory pensions scheme. The Council's work and establishment in several Western European countries were reduced, and the small cultural establishment in Germany was disbanded; university teachers were supplied to the Universities of Berlin ('Technical University), Göttingen, Hamburg and Mainz. Additional allocations were made for the cultural activities of the

* Report on the Work of the British Council, 1934-195.3. Pp. vi + . $12 t+6$ plates. (Twenty.First Anniversary Report.) (London : Britisi $12 t+6$ plates. (Twenty-
Council, 1955.) $2 s .6 d$. 
Brussels Treaty Organization (Western European Union and the Council of Europe). The Council's representation in New Zealend was withdrawn, and its establishments in Australia and Ceylon were closed; but work in Persia was resumed.

The number of students who were met on their first arrival from overseas reached the record total of $4,164,3,771$ being Colonial students, while new and better premises for this work among students were acquired in Aberdeen, Belfast, Edinburgh and Oxford. Two awards were made to university professors for short visits to the United Kingdom, and seven for visits to other Commonwealth countries, while forty-two travel grants were made to university teachers or postgraduate workers for study visits to the United Kingdom, ten for study visits from the United Kingdom and two for study visits between overseas countries. There were also forty-nine short visits to the United Kingdom universities and fortynine visits to foreign universities. Some twenty-nine lecture tours and advisory visits overseas were arranged in science, medicine, agriculture and engineering, and twenty-one in education, sociology, philosophy and law ; besides tours and exhibitions, the Council supplied about 82,000 books to Council and Council-associated libraries and secured 6,921 reviews of British books in overseas periodicals. Of the lecture tours arranged, 33 per cent were in medicine and science, and 25 per cent in education, while of the 1,488 film prints distributed in fifty-five countries, 216 were medical and 220 scientific and technical.

Most of the report is occupied by a historical review by Sir Harold Nicholson of the inception of the Council and the development of its work from 1934 to 1955, including a critical appreciation of that work. This is followed by an appreciation of its present activities by the new director-general, Sir Paul Sinker, and there is also an appreciation of Sir Ronald Adam's work by Sir Philip Morris. Since the end of the Second World War the Council has arranged programmes for 35,726 overseas visitors, mainly professional people or technicians, including many who have come under United Nations or Colombo Plan programmes; but the proportion of such visits financed wholly or in part by the Council has fallen from 66 per cent in 1945-46 to 16 per cent in 1954-55.

\section{LONG ASHTON RESEARCH STATION \\ REPORT FOR 1954}

A

CONSIDERABLE number of papers on various aspects of disease control is to be found in the report for 1954 of the Agricultural and Horticultural Research Station, Long Ashton, Bristol, which has recently been published*. Such a concentration in no way disturbs the general efficacy and breadth of the report, as it relates to other aspects of fruit culture and fruit products. It serves, rather, to integrate the results of several workers, thus giving a special, as well as a general, significance to an annual report of progress.

* University of Bristol. The Annual Report of the Agricultural and Horticultural Research Station (The National Fruit and Cider Institute), Jong Ashton, Bristol, 1954. Pp. $207+13$ plates. (Irong
Ashton: The Station, 1955.) 158.
On the question of materials for disease control, G. V. Coles, J. T. Martin and R. J. W. Byrde have investigated the fungicidal properties of coal-tar distillates against Ceratostomella fimbriata, causing mouldy rot of newly tapped bark of the rubber tree. The predominating effect of the phenol fraction in determining fungicidal efficiency was confirmed by chemical analysis and bioassay. R. J. W. Byrde and A. T. K. Corke found that sporulation of Nectria galligena on apple cankers was reduced for about eighteen months, following treatment with 0.3 per cent phenyl mercury chloride. Burgundy mixture has been used for a long period of years, but $\mathbf{E}$. Somers has demonstrated that the mixture $10 \mathrm{lb}$. copper sulphate, $14 \mathrm{lb}$. sodium carbonate, 100 gall. water, gives the best tenacity on potato foliage, when applied against blight. Post-dormant sprays of DDT and $\mathrm{BHC}$ kill some predators of the red spider mite; H. G. H. Kearns, N. G. Morgan and A. H. Wilkins have found that eggs of the mite can be controlled effectively by spraying with 0.05 or 0.02 per cent chlorbenside ( $p$-chlorbenzyl $p$-chlorphenyl sulphide). Applications were made at the pink-bud stage of Worcester Pearmain apples, and were not effective at earlier stages.

Specifications for two light-weight small-power sprayers are given by H. G. H. Kearns and N. G. Morgan. They use 34-c.c. and 70-c.c. petrol engines, and deliver 8 and 19 pints/min., respectively, both at $75 \mathrm{lb} . / \mathrm{sq}$. in. There is considerable interest in the relative efficacy and operational economy of small. volume air-flow spraying. Messrs. Kearns and Morgan have also found the method effective against potato blight, but the same authors, with R. W. Marsh, record that apple scab control using lime sulphur or captan required more air-flow applications to be as effective as large-volume spraying. Small-volume sprayings accentuate the need for studies on spraydroplet size and distribution. C. G. L. Furmidge has two papers on this question; one of them describes field methods in which droplets are estimated as impressions in magnesium oxide, or as stains on glass, plaster of paris or various paper surfaces. Methods for the assay of captan deposits are described by J. T. Martin and J. A. Pickard, while the distribution of copper and DDT deposits are discussed in relation to the method of application by $N$. G. Morgan and J. T. Martin. Finally, R. W. Marsh considers results on apple scab control over eleven years with a view to the formulation of a modern spray policy for the fruit grower. Results from 1954 are marshalled to the same end by R. J. W. Byrde, G. M. Clarke and C. W. Harper. The general conclusion from both these papers appears to be that captan and phenyl mercury chloride, among the newer fungicides, are most likely to find places in the normal spray schedule for apple varieties which are 'russeted' by lime sulphur.

The mycological side of plant pathology is represented by a paper by A. T. K. Corke, who finds that inoculations with mycelium of the bitter rot fungus Gloeosporium perennans on apple branches produced cankers at all times of the year. Inoculations with spore suspensions, however, were generally successful only in November and December. From the section of pomology, R. R. Williams, continuing an earlier study, has described a further eleven varieties of perry pears from Herefordshire and Gloucestershire. The same author has a final report on yields and orchard behaviour of thirty-two varieties of cider apples grown as bush trees during 1950-53, and pollen 